\title{
Gebelikte Yaşanan Reflünün Yaşam Kalitesi ve Gebelik Uyumuna Etkisi:
}

\author{
Vaka-Kontrol Çalışması
}

\section{The Effect of Reflux During Pregnancy on Quality of Life and Adaptation to Pregnancy: Case-Control Study}

\author{
Keziban AMANAK ${ }^{1}$
}

${ }^{1}$ Adnan Menderes Üniversitesi Sağlık Bilimleri Fakültesi Ebelik Bölümü, Aydın, Türkiye

ÖZ

\begin{abstract}
Amaç: Bu çalışma, gebelikte yaşanan reflünün yaşam kalitesi ve gebelik uyumuna etkisini incelemek amacıyla yapılmıştır. Yöntem: Araştırma uygun örnekleme ile seçilen gebelikte reflüsü olan (vaka grubu) 112, gebelikte reflüsü olmayan (kontrol grubu) 112 olmak üzere, toplam 224 gebe ile yürütülmüştür. Araştırma verileri, Kişisel Bilgi Formu, Yaşam Kalitesi Ölçeği ve Prenatal Kendini Değerlendirme Ölçeği-Gebeliğin Kabulü Alt Ölçeği ile toplanmıştır.

Bulgular: Araştırmada, vaka grubundaki gebelerin kontrol grubundaki gebelere göre yaşam kalitesi puan ortalamalarının daha düşük olduğu ve bu farkın istatistiksel olarak önemli olduğu bulunmuştur. Ayrıca araştırmada vaka grubundaki gebelerin gebelik uyumu puan ortalamalarının $(33.21 \pm 5.89)$ kontrol grubundaki gebelere göre $(27.13 \pm 3.84)$ daha yüksek olduğu ve yapılan istatistiksel analizde bu farkın önemli olduğu görülmüştür.

Sonuç: Bu çalışmada, gebelikte reflü yaşayan gebelerin yaşam kalitesi ve gebeliğe uyum düzeylerinin gebelikte reflü yaşamayan gebelere göre daha düşük olduğu sonuçlarına ulaşılmıştır.
\end{abstract}

Anahtar Kelimeler: Yaşam Kalitesi, Uyum, Reflü, Gebelik.

\section{ABSTRACT}

Objective: This study was conducted to investigate the effect of reflux experienced during pregnancy on quality of life and adaptation to pregnancy.

Methods: This study was conducted with a total of 224 pregnant women, 112 with reflux (case group) and 112 without reflux (control group) during pregnancy. Research data were collected with Personal Information Form, Quality of Life Scale, and Acceptance of Pregnancy Subscale of the Prenatal Self Evaluation Questionnaire.

Results: In the study, it was found that the average quality of life scores of the pregnant women in the case group was lower than the pregnant women in the control group and this difference was statistically significant. In the study, it was found that the mean scores of adaptation to pregnancy of the pregnant women in the case group (33.21 \pm 5.89$)$ were higher than the pregnant women in the control group (27.13 \pm 3.84$)$ and this difference was significant in the statistical analysis.

Conclusion: In this study, it was concluded that the quality of life and adaptation to pregnancy levels of pregnant women who had reflux during pregnancy were lower than those who did not experience reflux during pregnancy.

Key words: Quality of Life, Adaptation, Reflux, Pregnancy.

\section{GíRiș}

Gebelik her kadın için özel bir dönemdir ve beraberinde bazı fiziksel ve psikolojik rahatsızlıkları getirebilir. Gastrointestinal sisteme ait rahatsızlıklar gebelikte oldukça sık yaşanmaktadır. Bu rahatsızlıkların yaşanmasındaki en önemli faktör artan gebelik hormonları olarak gösterilmektedir. Gebelikte ortaya çıkan reflü oldukça rahatsız edici bir durum olup gebeliklerin \%30-50'sinde görülmektedir. Özellikle ilk trimester sonu, 2. trimesterda başlayıp son trimesterda iyice belirgin hale gelmektedir. Gebelik sırasında görülen gastrointestinal 
rahatsızlıkların çoğu anne ve fetus için hayati tehlike oluşturmaz ancak etkilenen kadınlarda yaşam kalitesi büyük oranda bozulur ve sık sık doktora başvurmaya bağlı olarak aynı zamanda ekonomik kayba neden olur $(1,2)$. Yaşam kalitesi, bireyin içinde bulunduğu kültür ve değerler yapısı içinde kendi yaşamını nasıl algıladığı olup, bireyin amaçları, umutları, standartları ve endişeleri ile ilişkilidir $(3,4)$. Gebelikte yaşanan reflünün yaşam kalitesi üzerindeki bu olumsuz etkileri dolaylı olarak gebeliğe uyum sürecini de olumsuz olarak etkileyebilmektedir. Uyum, bireyin kendi içinde ve çevresinde karşılaştığı değişiklikleri olumlu bir denge içinde sürdürebilmek için kullandığı yöntemler ve süreçler dizisidir (5). Gebelikte uyum sağlama ve annelik rolünü kazanmada güçlük yaşayan anne, gebelikte yaşadığı sorunlarla ilgili olarak gebeliğe ve bebeğe karşı olumsuz tutum geliştirebilmektedir $(6,7,8,9)$. Dolayısıyla gebelikte reflüde, yaşam kalitesi ve gebelik uyumu kavramları ayrıntılı incelenmesi gereken konular olarak karşımıza çıkmaktadır. Bu bilgilere dayalı olarak çalışmada; gebelikte yaşanan reflünün yaşam kalitesi ve gebelik uyumuna etkisinin incelenmesi amaçlanmıştır. Araştırma soruları:

(1) Gebelikte reflüsü olan ve olmayan gebeler arasında yaşam kalitesi açısından fark var midir?

(2) Gebelikte reflüsü olan ve olmayan gebeler arasında gebeliğe uyum açısından fark var midır?

\section{GEREÇ VE YÖNTEM}

$\mathrm{Bu}$ araştırma analitik, vaka-kontrol çalışması olarak, Aydın Kadın Doğum ve Çocuk Hastanesi Kadın Doğum polikliniklerinde 15 Haziran 2019-15 Şubat 2020 tarihleri arasında yapılmıştır. Araştırmaya uygun örnekleme ile seçilen gebelikte reflüsü olan (vaka grubu) 112, gebelikte reflüsü olmayan (kontrol grubu) 112 olmak üzere toplam 224 gebe dahil edilmiştir. Araştırmanın örneklemine dahil edilecek gebeler; Yanıkkerem ve Saruhan (2012)'ın 'Effect of Nursing Education on Sleep and Quality of Life Among Pregnant Women with Gastroesophageal Reflux Disease" başlıklı çalışmalarının (10) yaşam kalitesi ölçeği puan ortalamaları kullanılarak, t testi ile, etki gücü $d=0.45$ hesaplanmış, $\alpha=0,05, \% 95$ güven aralığında \%80 güce ulaşmak için araştırmaya alınması gereken en az gebe sayısı her bir grup için 62 olmak üzere toplam 124 gebe olarak hesaplanmıştır. Araştırmaya 20-37 yaş aralığında, gebeliğin üçüncü trimestırında olan (28-40 hafta arası), ilk gebelik ve tek fetüsa sahip olan gebeler dahil edilirken, herhangi bir gebelik komplikasyonu ve sistemik/nörolojik hastalığı olan gebeler araştırmadan dışlanmışlardır. Ayrıca araştırmaya dahil edilen gebelerden veri toplama formalarını tam olarak doldurmayan 8 gebe araştırmadan çıkarılmıştır.

Araştırma verileri; gebelerde reflü varlığını belirlemek için "Reflü Semptom İndeksi”, sosyo-demografik özelliklerin yer aldığı "Kişisel Bilgi Formu”, gebelerin yaşam kalitesini belirleyebilmek için "Yaşam Kalitesi Ölçeği” ve gebelerin gebeliğe uyumlarını değerlendirmek için "Prenatal Kendini Değerlendirme Ölçeği-Gebeliğin Kabulü Alt Ölçeği” ile toplanmıştır.

Reflü Semptom İndeksi (RSI): İndex 2002 yılında Belafsky ve arkadaşları tarafından geliştirilmiş olup larengofarengeal reflü varlığını tespit etmek için oluşturulmuş dokuz başlıklı bir indekstir (11). İndex puanının on ve üzerinde olması reflü varlığını ifade etmektedir. Skorlamada 0 problem yok olarak, 5 ise ciddi problem olarak kabul edilmektedir. RSI reflü varlığını tesbit etmek için yapılan çalışmalarda kullanılmış, güvenilir ve geçerli olduğu bulunmuştur $(12,13,14,15)$. Bu araştırmada Reflü Şiddet İndeksi'nden 10 ve üzeri puan alan gebeler vaka, 10 puanın altında alan gebeler kontrol grubuna dahil edilmişlerdir. 
Kişisel Bilgi Formu (KBF): Gebelerin yaşı, eğitim durumu, çalışma durumu, gelir durumu, aile yapısını sorgulayan toplam 5 sorudan oluşmaktadır $(1,8,10)$.

Yaşam Kalitesi Ölçeği (Short-Form Health Survey (SF-36) (YKÖ): Ölçek Ware ve Sherbourne tarafından 1992 yılında geliştirilmiştir (16). Ölçeğin Türkçe dil ve geçerlik güvenirlik çalışması Pınar (1995) tarafından yapılmıştır (17). Ölçek; fiziksel fonksiyon, sosyal fonksiyon, fiziksel fonksiyona bağlı rol kısıtlılıkları, emosyonel sorunlara bağlı rol kısıtlılıkları, mental sağlık, enerji/vitalite, ağrı ve genel sağlığın algılanması olmak üzere sekiz alt boyuttan ve 36 maddeden oluşmaktadır. Ölçeğin değerlendirmesinde her bir alt boyuttan 0-100 puan arasında puan elde edilmekte, 0 puan yaşam kalitesi boyutunun kötü olduğunu, 100 puan ise iyi olduğunu belirtmektedir (3).

Prenatal Kendini Değerlendirme Ölçeği- Gebeliğin Kabulü Alt Ölçeği (PKDÖ-GK): Ölçek Lederman ve ark. (1979) tarafından geliştirilmiştir (18). Bu araştırmada ölçeğin "Gebeliğin Kabulü Alt Ölçeği” kullanılarak kadınların gebeliğe uyumları değerlendirilmiştir. Ölçek; kendi ve bebeğinin iyi olması, gebeliğin kabulü, annelik rolünün tanımlanması, doğuma hazırlık, yardım/kontrol (doğumda yardım almama ve kontrol kaybı korkusu), eş ile ilişkiler ve anne ile ilişkiler olmak üzere yedi alt ölçek ve 79 maddeden oluşmaktadır. Ölçeğin Türkçe dil ve geçerlik güvenirlik çalışması Taşçı ve Mete (2008) tarafından yapılmış ve gebeliğin kabulü alt ölçeğinin iç tutarlık katsayısı 0.80 olarak bildirilmiştir. Bu alt ölçekten alınacak en yüksek puan 56 ve en düşük puan 14 olup, ölçekten alınan puanlar azaldıkça gebeliğin kabulü artmaktadır (19). Bu çalışmada gebeliğin kabulü alt ölçeğinin iç tutarlık katsayısı 0.78 olarak bulunmuştur.

\section{Etik prosedürler:}

Araştırmanın uygulanabilmesi için Aydın Kadın Doğum ve Çocuk Hastalıkları Hastanesi Başhekimliğinden yazılı izin alınmıştır. Araştırma protokolü Adnan Menderes Üniversitesi Sağlık Bilimleri Fakültesi Klinik Araştırmalar Danışma Komisyonu Etik Kurulu tarafından uygun bulunmuştur (2019/033). Araştırmaya dâhil edilen gebelere araştırma hakkında bilgi verilmiş, sözlü onamları alınmış, istedikleri takdirde araştırmadan ayrılabilecekleri hakkında bilgilendirilmişlerdir.

\section{İstatistiksel analiz:}

Araştırmanın istatistiksel analizi SPSS 18.0 programı ile yapılmıştır. Verilerin normal dağılama uygun olup olmadıklarının değerlendirilmesi Kolmogorov-Smirnov ve Shapiro-Wilk testleri yapılmıştır. Vaka ve kontrol gruplarındaki gebelerin sosyo-demografik özelliklerinin karşılaştırılmasında ki-kare, Yaşam Kalitesi Ölçeği ve Prenatal Kendini Değerlendirme ÖlçeğiGebeliğin Kabulü alt ölçeği puan ortalamalarının karşılaştırılmasında t testi kullanılmıştır.

\section{BULGULAR}

Çalışmaya katılan gebelerin sosyo-demografik özellikleri Tablo 1'de verilmiştir. Araştırmada vaka ve kontrol grubunda yer alan gebeler yaş, eğitim durumu, çalışma durumu, gelir durumu, aile yapısı gibi özellikler bakımından istatistiksel olarak karşılaştırılmıştır. Bu karşılaştırma sonucunda iki grup sosyo-demografik özellikler bakımından benzer olarak bulunmuştur. 
Tablo 1. Gebelerin Sosyo-Demografik Özellikleri

\begin{tabular}{|c|c|c|c|}
\hline Özellikler & Vaka grubu $(\mathrm{n}=112)$ & $\begin{array}{c}\text { Kontrol grubu } \\
(\mathrm{n}=112)\end{array}$ & $\mathbf{P}$ \\
\hline \multicolumn{4}{|c|}{ Eğitim durumu, n(\%) } \\
\hline İlköğretim & $68(60.7)$ & $65(58.0)$ & 0,546 \\
\hline Lise & $25(22.3)$ & $26(23.2)$ & \\
\hline Üniversite ve üstü & $19(17.0)$ & $21(18.8)$ & \\
\hline \multicolumn{4}{|c|}{ Calısma durumu, n(\%) } \\
\hline Çalışıyor & $26(23.2)$ & $28(25.0)$ & 0,358 \\
\hline Ev hanımı & $86(76.8)$ & $84(75.0)$ & \\
\hline \multicolumn{4}{|l|}{ Gelir durumu, n(\%) } \\
\hline İyi & $20(17.9)$ & $21(18.8)$ & 0,312 \\
\hline Orta & $65(58.0)$ & $64(57.1)$ & \\
\hline Kötü & $27(24.1)$ & $27(24.1)$ & \\
\hline \multicolumn{4}{|l|}{ Aile yapısı, $\mathbf{n}(\%)$} \\
\hline Çekirdek aile & $72(64.3)$ & $70(62.5)$ & 0,785 \\
\hline Geniş aile & $40(35.7)$ & $42(37.5)$ & \\
\hline Yaş, Ort $\pm \mathbf{S S}$ & $26.61 \pm 5.35$ & $25.12 \pm 4.78$ & 0,478 \\
\hline
\end{tabular}

Vaka ve kontrol grubunda yer alan gebelerin yaşam kalitesi puan ortalamaları incelendiğinde, vaka grubundaki gebelerin (genel sağlık algısı: 55.23 \pm 2.85 , fiziksel fonksiyon: 67.52 \pm 2.74 , fiziksel rol k1sitl1lıklar1: $70.85 \pm 4.63$, psikolojik rol kisitl1lıklar1: $74.63 \pm 3.45$, sosyal fonksiyon: $51.47 \pm 5.78$, ağri: $38.45 \pm 5.36$, vitalite: $58.96 \pm 6.79$, mental sağlik: $51.47 \pm 7.41$ ) kontrol grubundaki gebelere göre yaşam kalitesi puan ortalamalarının (genel sağlık algısı: 61.25 \pm 4.52 , fiziksel fonksiyon: $75.12 \pm 3.41$, fiziksel rol kısitl1lıkları: $78.14 \pm 5.78$, psikolojik rol kısitl11ıklarr: $81.14 \pm 4.31$, sosyal fonksiyon: $55.21 \pm 6.74$, ağr1: $44.23 \pm 7.41$, vitalite: $65.14 \pm 3.52$, mental sağlık: $57.21 \pm 4.96$ ) daha düşük olduğu ve bu farkın istatistiksel olarak önemli olduğu bulunmuştur ( $<$ 0.001) (Tablo 2).

Tablo 2. Gebelerin Yaşam Kalitesi Puan Ortalamalarının Dağılımı

\begin{tabular}{lccc}
\hline YKÖ & $\begin{array}{c}\text { Vaka grubu }(\mathbf{n}=\mathbf{1 1 2}) \\
\text { Ort } \pm \mathbf{S S}\end{array}$ & $\begin{array}{c}\text { Kontrol grubu }(\mathbf{n}=\mathbf{1 1 2}) \\
\text { Ort } \pm \mathbf{S S}\end{array}$ & P \\
\hline Genel sağlık algısı & $55.23 \pm 2.85$ & $61.25 \pm 4.52$ & $\mathrm{p}<0.001$ \\
\hline Fiziksel fonksiyon & $67.52 \pm 2.74$ & $75.12 \pm 3.41$ & $\mathrm{p}<0.001$ \\
\hline Fiziksel rol kısıtlılıkları & $70.85 \pm 4.63$ & $78.14 \pm 5.78$ & $\mathrm{p}<0.001$ \\
\hline Psikolojik rol kısıtlılıkları & $74.63 \pm 3.45$ & $81.14 \pm 4.31$ & $\mathrm{p}<0.001$ \\
\hline Sosyal fonksiyon & $51.47 \pm 5.78$ & $55.21 \pm 6.74$ & $\mathrm{p}<0.001$ \\
\hline Ăgrı & $38.45 \pm 5.36$ & $44.23 \pm 7.41$ & $\mathrm{p}<0.001$ \\
\hline Vitalite (enerji, canlılık) & $58.96 \pm 6.79$ & $65.14 \pm 3.52$ & $\mathrm{p}<0.001$ \\
\hline Mental sağlık & $51.47 \pm 7.41$ & $57.21 \pm 4.96$ & $\mathrm{p}<0.001$ \\
\hline
\end{tabular}

Araştırmada vaka grubundaki gebelerin gebelik uyumu puan ortalamalarının (33.21 \pm 5.89$)$ kontrol grubundaki gebelere göre $(27.13 \pm 3.84)$ daha yüksek olduğu ve yapılan istatistiksel analizde de bu farkın önemli olduğu saptanmıştır $(\mathrm{p}<0,001)$ (Tablo 3$)$.

Tablo 3. Gebelerin Gebelik Uyumu Puan Ortalamalarının Dağılımı

\begin{tabular}{lccc}
\hline \multirow{2}{*}{ PKDÖ-GK } & Vaka grubu $(\mathbf{n}=\mathbf{1 1 2})$ & Kontrol grubu $(\mathbf{n}=112)$ & P \\
& Ort $\pm \mathbf{S S}$ & Ort $\pm \mathbf{S S}$ & \\
\cline { 2 - 4 } & $33.21 \pm 5.89$ & $27.13 \pm 3.84$ & $<0,001$ \\
\hline
\end{tabular}




\section{TARTIŞMA}

Gebelikte yaşanan reflünün yaşam kalitesi ve gebelik uyumuna etkisini incelemek amacı ile analitik tipte, vaka-kontrol çalışması olarak yapılan bu çalışmada, gebelikte reflü yaşayan gebelerin yaşam kalitesi ve gebeliğe uyum düzeylerinin gebelikte reflü yaşamayan gebelere göre daha düşük olduğu sonuçlarına ulaşılmıştır. Bu sonuçlar, gebelikte oldukça sık görülen reflünün önlenmesi ya da semptomların hafifletilmesine yönelik girişimlerin planlanması ve bu girişimlerin uygulanması konusunun önemini göstermesi bakımından önemlidir.

$\mathrm{Bu}$ çalışmada vaka ve kontrol gruplarında yer alan gebelerin sosyo-demografik özelliklerinin benzer olması, grupların yaşam kalitesi ve gebeliğe uyum düzeyleri bakımından karşılaştırılabilir özellikte olduğunu göstermesi açısından önemlidir.

Araştırmada, vaka grubunda yer alan gebelerin yaşam kalite düzeyleri kontrol grubundaki gebelere göre istatistiksel olarak anlamlı derecede düşük olarak bulunmuştur. Fill ve ark. (2017) bu çalışmanın sonuçlarına benzer olarak, 510 gebe ve 330 gebe olmayan kadınla prospektif olarak yaptıkları çalışmada; gebelikte reflü şikayeti yaşayan kadınların gebe olmayan kadınlara göre yaşam kalite düzeylerinin daha düşük olduğunu bildirmişlerdir (4). Ancak yapılan literatür taramasında gebelikte reflü şikayeti ile yaşam kalitesi ilişkisinin incelendiği çalışma sayısının oldukça az olması, ayrıca gebelikte reflü şikayeti yaşayan ve yaşamayan gebelerin yaşam kalitesi düzeylerinin karşılaştırıldığı herhangi bir çalışmaya ulaşılamaması, bu konuda daha fazla çalışmaya ihtiyaç duyulduğu göstermesi bakımından önemlidir.

Literatürde gebeliği kabullenmede sorun yaşayan kadınların, gebelik ve annelik rolüne ilişkin uyum sorunu yaşadıkları ve bu durumun anne- bebek sağlığını olumsuz olarak etkilediği bildirilmektedir (20,21). Bu araştırmanın sonuçlarına göre gebelikte reflü sorunu yaşayan kadınların gebeliğe uyum düzeyleri, gebelikte reflü yaşamayan kadınlara göre istatistiksel olarak anlamlı derecede daha düşük bulunmuştur. Oysa ki kadınların gebelik ve annelik rolüne ilişkin uyum sağlaması ve başarması için etkili olabilecek faktörlerin belirlenmesi, riskli durumların erken tanılanması ve gerekli önlemlerin alınması ile optimal anne-bebek sağlı̆̆ına ulaşılabilir. Ancak yapılan literatür taramasında gebelikte reflünün gebelik uyumuna etkisini inceleyen herhangi bir çalışmaya ulaşılamamıştır. $\mathrm{Bu}$ sonuç gebelikte reflünün gebelik uyumuna etkisini inceleyen çalışmalara ihtiyaç duyulduğu göstermesi bakımından önemlidir.

$\mathrm{Bu}$ araştırmanın bazı sınırlılıkları bulunmaktadır. Araştırmada kullanılan veri toplama araçları özbildirim yöntemi ile toplanmıştır. Bu formların doldurulması ile elde edilen veriler uzman kişiler tarafından gözlemlenen durumlardan farklı olabilir. Ayrıca araştırmanın tek merkezde ve uygun örnekleme yöntemi ile yapılmış olması nedeniyle elde edilen sonuçlar sadece bu araştırmanın örneklemini temsil etmektedir.

\section{SONUÇ}

Bu çalışmada, gebelikte reflü yaşayan gebelerin yaşam kalitesi ve gebeliğe uyum düzeylerinin gebelikte reflü yaşamayan gebelere göre daha düşük olduğu sonuçlarına ulaşılmıştır. Bu sonuçlar gebelikte reflü sorununun önlenmesi ya da semptomların azaltılmasına yönelik gerekli önlemlerin alınması gerektiğini vurgulamaktadır. Bu noktada gebelerle daha fazla bir arada bulunan sağlik profesyonellerinden; hemşire ve ebelere önemli görevler 
düşmektedir. Hemşire ve ebeler, gebelerin yaşadıkları reflü şikayetine yönelik önleyici uygulamalar ile gebelerin yaşam kalitesinin artırılması, gebeliği kabullenme ve gebeliğe uyum süreçlerine olumlu katkı sağlayabilirler.

\section{Araştırmanın Etik Yönü}

Araştırmanın uygulanabilmesi için Aydın Kadın Doğum ve Çocuk Hastalıkları Hastanesi Başhekimliğinden yazılı izin alınmıştır. Araştırma protokolü Adnan Menderes Üniversitesi Sağlık Bilimleri Fakültesi Klinik Araştırmalar Danışma Komisyonu Etik Kurulu tarafından uygun bulunmuştur (2019/033). Araştırmaya dâhil edilen gebelere araştırma hakkında bilgi verilmiş, sözlü onamları alınmış, istedikleri takdirde araştırmadan ayrılabilecekleri hakkında bilgilendirilmişlerdir.

\section{KAYNAKLAR}

1. Aygün, C., \& Kumbak, A. B. (2010). Gebelik ve konstipasyon. İn̈nü Üniversitesi Tıp Fakültesi Dergisi, 17(1), 71-75.

2. Dağlı, Ü., \& Kalkan, İ. H. (2017). Gebelik ve laktasyonda reflü hastalığının tedavisi. Turk J Gastroenterol, 28(1), 53-56.

3. Özhüner, Y., \& Çelik, N. (2019). Gebelerde uyku kalitesi ve yaşam kalitesi. HSP, 6(1), 39-47.

4. Fill Malfertheiner, S., Seelbach-Göbel, B., Costa, S. D., Ernst, W., Reuschel, E., Zeman, F., \& et al. (2017). Impact of gastroesophageal reflux disease symptoms on the quality of life in pregnant women: a prospective study. Eur J Gastroenterol Hepatol, 29(8), 892-896.

5. Roy, C. (2009). The Roy Adaptation Model. 3rd ed, New Jersey Upper Saddle River: Pearson Prentice Hall Health,

6. Lee, L. Y. K., Tsang, A.Y. K., Wong, K. F., \& Lee, J. K. L. (2011). Using the Roy Adaptation Model to develop an antenatal assessment instrument. Nursing Science Quarterly, 24(4), 363-369.

7. Elizabeth, N. (2011). Maternal role development: The impact of maternal distress and social support following childbirth. Midwifery, 27(2), 265-272.

8. İşbir, G. G., \& Mete, S. (2013). Experiences with nausea and vomiting during pregnancy in Turkish women based on Roy Adaptation Model: A content analysis. Asian Nursing Research, 7, 175-181.

9. Weis, K. L. (2006). Maternal 1dentity formation in a military sample: A longitudinal prespective, theses of $\mathrm{PhD}$ : University of North Carolina.

10. Yanıkkerem, E., \& Saruhan, A. (2012). Effect of Nursing Education on Sleep and Quality of Life Among Pregnant Women with Gastroesophageal Reflux Disease. F.Ü.Săg.Bil.Tıp Derg, 26(1), 07-14.

11. Belafsky, P. C., Postma, G. N., \& Koufman, J. A. (2002). Validity and reliability of the reflux symptom index (RSI). Journal of Voice, 16(2), 274-7.

12. Günel, C., Günel, S., \& Ömürlü, İ. K. (2012). Larengofarengeal reflü ve gastroözafageal reflü hastalığı arasında semptomatik ve endoskopik ilişsinin karşılaştırılması. KBB Forum, 11(3), 56-61.

13. Karaaltın, A. B., Develioğlu, Ö. N., Tarhan, Ö., \& Külekçi, M. (2016). The importance of voice analysis in evaluating the effectiveness of reflux treatment. Kulak Burun Bogaz Ihtis Derg, 26(4), 207-212. 
14. Ezerarslan, H., Çoban, M., Kuran, S., Akmansu, Ş. H., Özgüler, Z., Beriat, G. K., \& ve ark. (2012). The relationship between heterotopic gastric mucosa in the cervical esophagus and laryngopharyngeal reflux. Kulak Burun Bogaz Ihtis Derg, 22(1), 6-11.

15. Verim, A., Şeneldir, L., Naiboğlu, B., Karaca, Ç. T., Kadığlu, D., \& Toras, S. Z. (2016). Effect of laryngopharyngeal reflux on the improvement of chronic rhinosinusitis without polyposis after primary endoscopic sinus surgery. Kulak Burun Bogaz Ihtis Derg, 26(2), 65-72

16. Ware, J. E., Sherbourne, C. D. (1992). The MOS 36-item Short-Form Health Survey (SF-36): I. Conceptual framework and item selection. Medical Care, 30(6), 473-83.

17. Pınar, R. (1995). Sağlık araştırmalarında yeni bir kavram: Yaşam kalitesi, bir yaşam kalitesi ölçeğinin kronik hastalarda geçerlik ve güvenirliğinin sınanması. Hemşirelik Bülteni, 9, 85-95.

18. Lederman, R., \& Lederman, E. (1979). Relationship of psychological factors in pregnancy to progress in labor. Nursing Research, 28(4), 94-97.

19. Taşç1, K. D. B., \& Mete, S. (2008). Prenatal kendini değerlendirme ölçeğinin geçerlik ve güvenirlik çalışması. Atatürk Üniversitesi Hemşirelik Yüksekokulu Dergisi, 11(1), 16-24.

20. Demirbaş, H., \& Kadıoğlu, H. (2014). Prenatal dönemdeki kadınların gebeliğe uyumu ve ilişkili faktörler. $M \ddot{U} S B E D, 4(4), 200-206$.

21. Amanak, K., Sevil, Ü., \& Karaçam, Z. (2019). The impact of prenatal education based on the Roy adaptation model on gestational hypertension, adaptation to pregnancy and pregnancy outcomes. JPMA, 69(1), 11-17. 